\title{
Development and Implementation of Innovative Practical Projects Based on Electronic Contests
}

\author{
Honghui Mu ${ }^{1, a^{*}}$, Ying Zhao ${ }^{1, b}$ and Wei Zhang ${ }^{1, c}$ \\ ${ }^{1}$ School of information engineering, Changchun Sci-Tech University, Changchun 13000, China \\ amuhonghui@foxmail.com, b17920903@qq.com, 674175254@qq.com
}

Keywords: Innovation; Practice project; Electronic Contest

\begin{abstract}
Based on the opportunity of college students' electronic competition, with the experience of guiding students attend the national contest of electronic practice, this paper constructed a comprehensive innovation practice project system, perfected the training course system and put forward the electronic competition training method of comprehensive project development, then developed the CPLD/FPGA and SCM based on the guidance of the students' participation in the national electronic competition in this paper. Finally, gave the concrete implementation method and combined with the characteristics of students. The practice proved that this method is beneficial to cultivate students' innovative ability and improving their practical ability.
\end{abstract}

\section{Introduction}

The electronic design competition for college students is joint initiated, organized and conducted by the ministry of education and the personnel division of the ministry of information industry, it is one of the seven major disciplines of national universities [1]. Organizing college students to participate in electronic competitions can improve students' practical ability, practical project design ability and comprehensive design ability of production. Specific training is generally required before competition, CDIO engineering teaching model points out the methods and approaches for the cultivation of students' innovative entrepreneurial ability, this model advocates the cultivation of students' engineering abilities through conception, design, implementation and operation. The electronic design competition mode which based on CDIO not only cultivate students' practical innovation awareness and ability, but also improve teamwork spirit, it is helpful for cultivating students' engineering practice quality, improving students' electronic design ability and solving problems ability , then creating conditions for outstanding talents[2].

\section{Innovation Practice Project Implementation System Construction}

The organization and training of electronic design competition has the characteristics of large time span, more practical projects and difficult implementation. In order to organize and train the electronic design competition, it necessary to build a complete training system, which includes the electronic design competition guidance team, the electronic design competition innovation association, the electronic design competition innovation base organization and establishment, and the electronic design competition ladder training establishment.

Organization and Establishment of Electronic Design Competition Guidance Team. In view of the heavy task of undergraduate teaching assignments in electronic information science and technology, the characteristics of the teachers are the numbers limited, scientific research pressure high, lack experience and so on. Organization and establish of electronic design contest guidance team take the following ways: invite the dean of electronic science and technology of the college to serve as the main leadership of the team, the dean as the main leadership of the team, a skilled and experienced teacher are invited as a team leader in technical training, invite three professional laboratory technicians to be responsible for the technical implementation, fund management, logistics support and external communication, the students who have participated in the electronic design competition and have rich 
experience in the field of electronic design competition are invite to conduct the ladder training for the new students, invite experts or professors in the corresponding field to dispel doubts when face of special problems.

Organization and Establishment of the Innovation Association of Electronic Design Competition. In the past, students who participated in electronic design competitions are selected directly from second grade and third-grade students, the result of the match is third grade is more excellent than second grade. This temporary selection need to students and teachers pay more labor in a short time, the students who really get good grades are those who have been interested in the electronic design and hard efforts in their spare time during their freshman year. Therefore, it is imperative to establish an electronic design competition innovation association, through the establishment of the association, the students who are truly interested in electronic design are recruited to guide properly in their spare time, then stepwise training and assessment them during the winter and summer vacation, we layer selected students through theoretical courses, practical courses, training scores, comprehensive test scores and interviews, recruit students with strong ability of innovation, practice and communication. Finally, the trainees are recruited to participate in the electronic design competition.

Organization and Establishment of the Innovation Base of Electronic Design Competition. Establish a humanized, fully open laboratory management model, full open practice teaching content, experiment device and teaching mode are constructed, build a practical training plan based on innovative talent cultivation, and establish a fully open source of practical teaching resources. Innovative laboratory specifications, full open management mechanism and other measures provide a solid material basis and institutional guarantee for discipline competitions. The practical situation of our university is tight budget of electronic design competition, limited space and shortage of teacher resources. The innovation base that can hold more than 20 students has been established, and created a series of management regulations, such as student management standard and student entrance innovation base agreement.

The innovation base is managed by two teachers, with the students' independent management, independent practice and self-improvement. The innovation base provides a number of ordinary instruments and a small amount of precision testing instruments for innovation practice and electronic design competition, a set of welding platform, soldering iron and heat blower, one set of simple PCB board equipment, and a drilling equipment. A set of electronic design contest basic development kit and components and so on. All functions can provide a temporary platform for the electronic design contest to provide innovative training.

Organization and Establishment of Training at the Stage of Electronic Design Competition. The test questions of College Students' electronic design competition have the characteristics of strong practicality, high comprehensiveness and great leeway, involving many specialized courses of electronic information, investigating the ability to assess the students' innovative thinking and the comprehensive application of basic knowledge. The scope of topic selection for the National College Students' electronic juice competition is based on the application and design of Electronic Technology mainly (including analog and digital circuits). It can involve single chip, programmable devices and microcomputers (the main development of microcomputers). It should take into account the basic requirements of teaching and give consideration to the development of new technologies as well as guide the reform of teaching content and curriculum system. According to the actual situation of the school resources and the overall level of the students, the main training types of the current and future students of the school are as follows: the type of instrument and the control type. The guidance team preliminarily refines the type of the students' training, and gives the steps of the ladder training for the electronic design competition: basic skills training, professional curriculum knowledge training, electronic design pattern training, electronic design system training, electronic design sprint training and other stages. CDIO based active project driven practice teaching mode is shown in Figure 1[4]. 


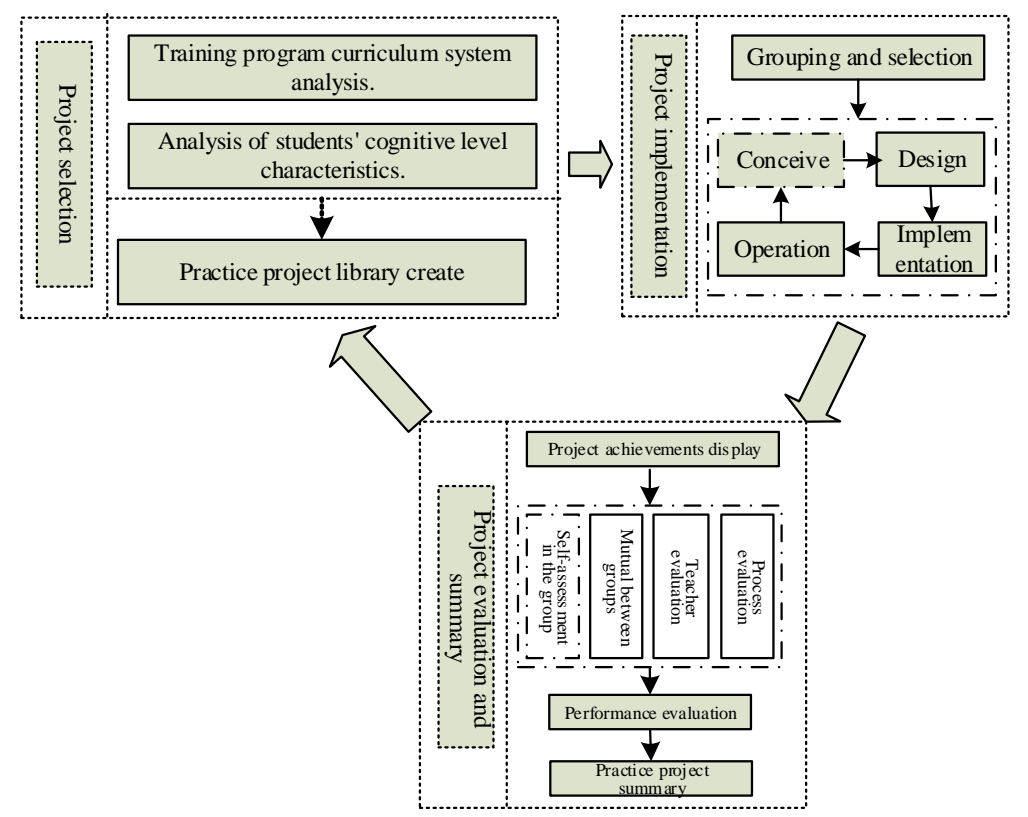

Figure 1 Based on CDIO active project driven practice teaching mode

\section{Innovation and Practice Project Development}

Development of CPLD/FPGA Project. Throughout the previous competition, the data collection and system control topics focus on digital circuits and control characteristics, and some functions can be implemented using CPLD / FPGA. Using CPLD / FPGA completely or combining it with a small number of digital devices or single chip microcomputer can often establish a system model. The students in the competition are senior and low grade, especially for the lower grade students. Because of the professional curriculum, their professional knowledge is not comprehensive enough. The DSP, SCM and automatic control principles have not been studied. As long as CPLD / FPGA has a little digital circuit and the basic knowledge of computer software design, the basic design methods and development skills can be mastered in the short term. Our pre competition training not only enables the senior students to choose the method to complete the competition flexibly, but the students in the lower grade can also really take part in thinking, write some modules or help the simulation program.

The project teaching method is suitable for learning all kinds of practical and operational knowledge and skills, and it is requires clear design purposes of each project, specified time limit and quality standard. Because of the detailed design requirements and scoring standards published every year by the organizing committee, the students can divide the digital logic parts which can be completed by CPLD /FPGA according to the requirements of the title, and make clear the connection between them and the other chips used by the system, and can focus on how to program the functional requirements. Competition from the title to the completion of the work only four days, this requires the use of CPLD / FPGA design part to be completed within 1 2 days, after training, the students master the design, is to achieve this goal. Therefore, in pre competition training, we should focus on project training. The training project level and teaching goal of PLC as shown in table 1.

\section{Integrated Project Implementation Method Based on Competition}

The senior students who participate in the electronic competition are the senior students of the engineering major. They have mastered the theory of electronic design through the study of basic courses and basic courses for several years, but they often not be used in the design and development of electronic projects well. In this regard, we propose a training method based on integrated project development. With comprehensive project as the carrier and method of method training, students can 
find problems, solve problems and accumulate experience in the design and development of comprehensive project [5]. The implementation process of specific projects is shown in Figure 2.

Table 1 PLC Training project level and teaching goal

\begin{tabular}{|c|c|c|c|}
\hline Level & Requirement & Target & Ability \\
\hline Primary & $\begin{array}{c}\text { Site layout topic, class } \\
\text { independent completion }\end{array}$ & $\begin{array}{c}\text { Understanding of PLC basic } \\
\text { structure and programming } \\
\text { environment. }\end{array}$ & $\begin{array}{c}\text { Build students' interest and } \\
\text { confidence in practice. }\end{array}$ \\
\hline $\begin{array}{c}\text { Intermed } \\
\text {-iate }\end{array}$ & $\begin{array}{c}\text { The site layout title, the } \\
\text { teacher gives appropriate } \\
\text { guidance }\end{array}$ & $\begin{array}{c}\text { Able to design simple PLC } \\
\text { electrical control system } \\
\text { independently }\end{array}$ & $\begin{array}{c}\text { Develop students' independent } \\
\text { design ability for a slightly more } \\
\text { complex electrical control } \\
\text { system }\end{array}$ \\
\hline $\begin{array}{c}\text { Senior } \\
\text { design,. According to the } \\
\text { degree of difficulty to } \\
\text { choose to complete } \\
\text { independently or } \\
\text { according to the division } \\
\text { of labor, teachers give } \\
\text { appropriate guidance. }\end{array}$ & $\begin{array}{c}\text { Master the structure design } \\
\text { idea of the complicated PLC } \\
\text { electrical control system, and } \\
\text { complete some module design. }\end{array}$ & $\begin{array}{c}\text { Train students on the mon } \\
\text { design ability and team spirit of } \\
\text { the more complex electrical } \\
\text { control system. }\end{array}$ \\
\hline
\end{tabular}

The Contest Topic Analysis. Before training, we should analyze and summarize the competition topics. The competition topics in recent years can be divided into four main categories: communication, measurement, control and power supply. The subdivision includes the subject of motion control, high precision and high speed instrument production, power production class, radio frequency transceiver system class, signal collection class, signal amplification class, etc. There are oscillators, filters, amplifiers, CPLD, TTL circuits, single chip and so on. The knowledge points used in power production topics include A/D, D/A, DDS, voltage stabilizing circuit, single chip, and so on. Radio frequency transceiver topics include modulation and demodulation circuit, RF power amplifier circuit, filter circuit. Signal class topics include operational amplifier circuit, waveform generation circuit, filter circuit and so on.

Screening Students to Form a Project Development Group. The development of the project involves the cultivation of many aspects of ability, such as the comprehensive ability of electronic design and production, the design and development ability of single chip microcomputer, the design and development ability of programmable logic device, and the ability of computer application. The development of the project needs a combination of many people. First, select the student composition development group. When organizing teams, each group should try to select an organization capable student responsible for the overall development of the project. Equipped with a hobby of electronic comprehensive design, a hobby single chip, a hobby CPLD students, so that each group of students can play a role in the development of their own interests in the project.

Selecting the Appropriate Project. The training takes the comprehensive project as the carrier, chooses a set of suitable comprehensive electronic design project to each development group. The project can start from the simple, according to the different development ability and the training schedule of each group, increase the difficulty of the project. From the verification project, gradually entered the actual combat projects, development projects. For example, the first project can be connected with the design of electronic technology courses to develop a simple project, "digital clock design based on single chip computer", in order to make students master the basic process and the work to be completed. With the improvement of students' level, the development projects of practical value are put forward, and they can even guide the students to put forward projects according to their life experience, such as "full automatic watering system", "solar lighting system" and so on. 


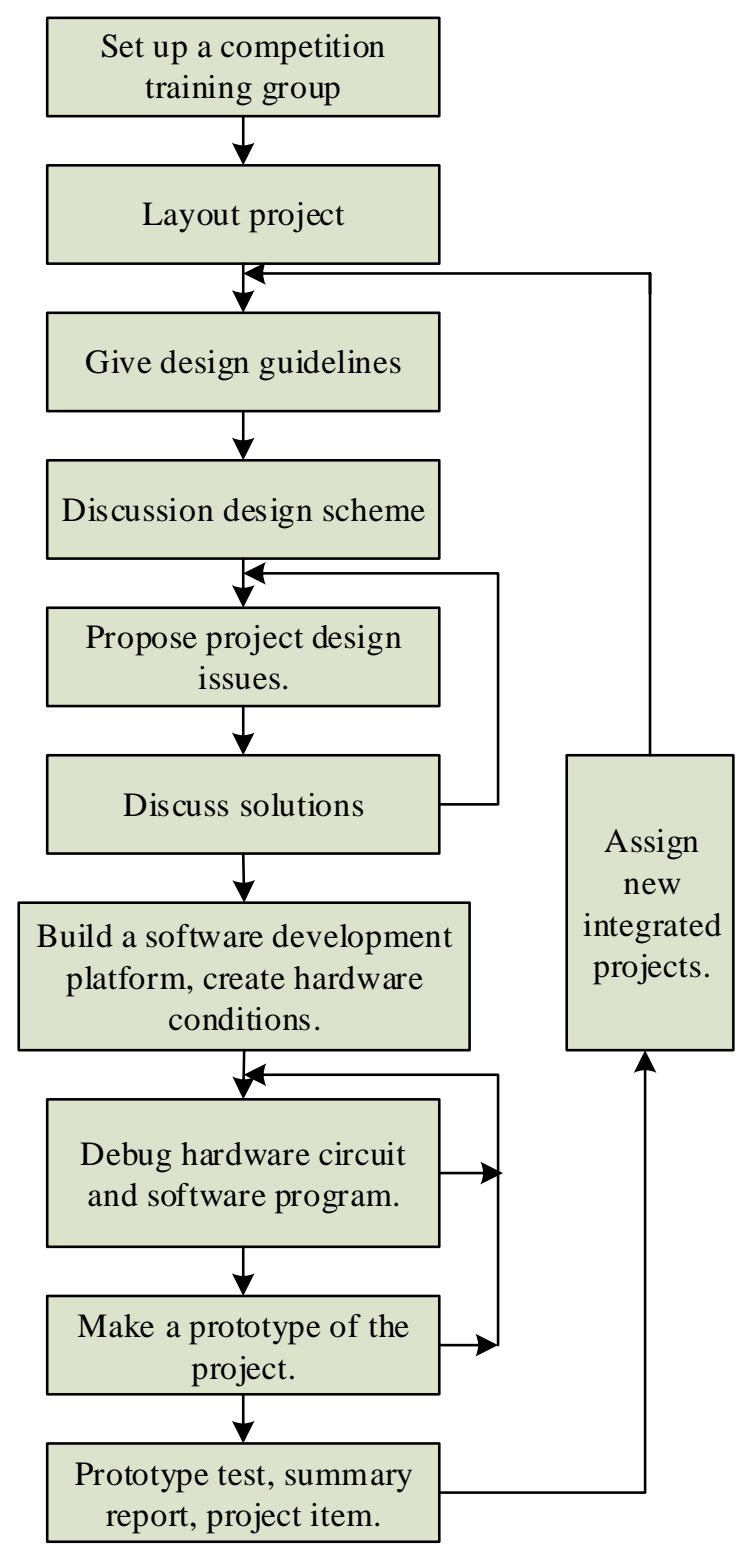

Figure 2 The implementation process of specific projects

Giving the Guiding Ideology of Design and Guide Students to Carry Out Academic Discussion. Method training should be taken as a means. In the training, the guiding ideology of solving problems should be given according to the different stages of the project development, and the students should be guided to discuss the problems around the problem. For example, in the initial stage of the project, give the guiding ideology of project design and guide students. The overall plan of the project is discussed and a reasonable overall plan is selected. In the specific design of the digital clock design based on single chip computer, the selection of input keys is given, and the general idea of key design is given, and the students will be guided to discuss the various methods and characteristics of the key implementation of the existing man-machine interface. By discussing and summarizing the parallel input mode, serial input mode, static input mode, dynamic scanning input mode, special chip mode, encoding input mode, contact input mode and wireless remote control mode, the mode selection and design problem of the input key on the digital clock are not only solved, but also the selection and design of the input key on the digital clock are not only solved. It effectively accumulated the design experience of the student's human-machine interface input interface.

Providing Design Platform to Create Hardware Conditions for Project Development. Each team is required to finish the prototype production of the comprehensive project. After completing the theoretical design of the system, the students need to make further hardware and debug the prototype. Note that in this process, each team needs to be equipped with adaptive system development platform and electronic product manufacturing device. If a digital clock system based on single chip is made, it is 
necessary to provide the students with the 5L series based SCM development platform, the microcontroller minimum system and the pinhole circuit board for the installation of electronic components. Only with the reasonable design platform and the hardware conditions can the training of the electronic race be successfully carried out, and the participation is also involved. Electronic competition preparation, good competition platform.

Prototype Test. Summarize project development experience and submit final report. At the end of each project, the technical indexes of the prototype are evaluated according to the project task book, the problems encountered in the project development process are summarized, and the solutions are found out. The technical drawings, software programs and circuit templates made in the course of the project are integrated. After submitting a project report, after completing a project, repeat the above training steps according to the quality and layout of the new comprehensive development project.

\section{Summary}

The electronic design contest not only effectively tests the quality of practical education in universities, but also promotes the development of innovative practical education. The electronic design competition training model based on the CDIO engineering education concept can train a team with a solid theoretical foundation and very strong practical ability, and has achieved excellent results in the electronic design competition. At the same time, taking the training of electronic design competition as an opportunity to improve the training mode of students' engineering practice ability, and gradually improve and popularize, make the college practice innovation education reach a new height and cultivate more excellent engineering talents for the society.

\section{Acknowledgements}

This work was 2017 Higher Education Academy subject in Jilin province; Project approval no.:JGJX2017D282.

\section{References}

[1] Li ZHANG, Li HE, Peng XU. Training mode of CDIO-Based Electronic Design Contest. 2nd Teaching Seminars on Higher Education Science and Engineering Courses. Taian, 2012.11, p. 864-866.

[2] Zhou Y, Wen-Jun H. Design and Application of CDIO Teaching Mode in Electronic Design Contest. Journal of Suzhou Vocational University. Vol. 21 (2010) No. 2, p. 71-73.

[3] Wang, Yong. "Enhancing Undergraduates' Innovation Ability Based on the Electronic Design Contest." Chinese Geological Education (2009).. Vol. 42 (2008) No. 11, p. 231-236.

[4] L.Y. Ling, Y.R. Huang, et al. Discussion on the Practical Teaching Reform of Electronic Information Major from Electronic Design Contest. ETMI 2016. (Shenzhen, China, October 30-31, 2016), Vol. 01 p.356.

[5] Wang, An Hong, and W. U. Wei-Xiong. "An E-contest Training Method Based on the Development of Integrated Project." Journal of Jiaxing University (2009) 